\title{
Can We Programme Utopia? The Influence of the Digital Ne- oliberal Discourse on Utopian Videogames
}

\author{
Luis Navarrete-Cardero* and Juan J. Vargas-Iglesias** \\ *University of Seville, Seville, Spain, Inavarrete@us.es \\ **University of Seville, Seville, Spain, jjvargas@us.es
}

\begin{abstract}
This article has a dual purpose. The first is to establish the relationship between videogames and utopia in the neoliberal era and clarify the origins of this compromise in the theoretical dimension of game studies. The second is to examine the ways in which there has been an application of the utopian genre throughout videogame history (the style of procedural rhetoric and the subgenre of walking simulator) and the way in which the material dimension of the medium ideologically updates the classical forms of that genre, be it through activation or deactivation. The article concludes with an evaluation of the degree in which the neoliberal discourse interferes with the understanding of utopia on behalf of the medium and with its imaginary capabilities to allow for an effective change in social reality.
\end{abstract}

Keywords: capitalism, utopia, videogame, walking simulator, procedural rhetoric

Acknowledgement: The authors would like to express their gratitude to the reviewers of this article and to Christian Fuchs for their feedback and suggestions.

\section{Introduction}

Having its origins in the 17th-century English and French utopian modes, politically focused on pragmatism and optimism respectively (Racault 1991, 33-150), and initially rejected by the Marxist left before being appropriated by philosophers like Ernst Bloch and Herbert Marcuse in the 1960s (Monticelli 2018), the utopian genre represents a reliable index of the capability of societies to envision their best possible future. More specifically, when understood as a product of humanism, the utopian genre attempts to overcome the historical contradiction between intellectual autonomy and political dependence (Balasopoulos 2008).

In this regard, the imposition of capitalism's own interpretation of such an overcoming has brought on a decadence of the genre's principles. As for the nature of utopia, the insertion of videogames in this context is of semiotic interest in at least two regards: as a form of expression, i.e. as a cybertextual medium characterised by its singular expressive faculties, and as a form of content, i.e. as an enunciable discursive device within the limits allowed by its singularity as a medium.

This article has the purpose of answering two specific questions: 1) can we strictly speak of the possible existence of a link between utopia and videogames? and 2) what are the possibilities offered by this link, in case it does exist, of transcending the formalist conception of ludology?

To answer these questions, this article is organised into the following sections: in Section 2 (Background), the current state of the concept of utopia in neoliberal society is estimated and its possibility is found in the epistemological reality of game studies, consequently considered to have inherited the cybernetic project of neoliberal 
society in that it was collectively founded in the principles established by ludology. Finally, the role that the cultural reason plays in capitalist societies and the resignification, from the onset of economic liberalism, of said reason as a means of escape are analysed. In Section 3 (Case and Methods), the research question is found in the sociological problematic originating from erasing the borders in the work-play relationship. Additionally, two historical occasions in which videogames were focused around a utopian purpose are referenced: procedural rhetoric videogames and walking simulators.

In Section 4, these variants of videogames - a style and a genre respectively are analysed in a separate manner in relation to the utopian potential of the medium. In the first case, a critique of proceduralism is made based on the enthymemic foundation of its proposal, the latter a result of its strictly formalist structure. In the second, the reflective effect that occurs in utopia when it refers to a dimension strictly belonging to daily life is analysed. This effect takes place when it moves away from the possibility of a global systemic change: a distinction is also made regarding the sense in which this effect, while implying a 'from-the-bottom-up' construction, opposes the set goals and economic performance-dominated formats. In Section 5 (Discussion and General Conclusions), the research questions will be answered and discussed, using the conclusions of each part of Section 4 as a reference.

\section{Background}

Posing a question about the programming of utopia in the title of our article is a statement of intent; indeed, such an enquiry demands that videogames possess a degree of responsibility of a social, political, and human complexion identical to that historically expected of literature and film. Just as has been a fundamental objective of both of these media, the goal of videoludic expression should be to transcend the very form of the videogame by demonstrating an integrated approach to human values, thereby participating in an active form of humanism. Such a demand does not seek to bring the expressive autonomy of videogames into question, nor does it intend to put strain on their ontological nature or sustain such a nature at any cost. We are aware of the theoretical resistance emerging from certain sections of the game studies community, which are extremely preoccupied with compartmentalising, delimiting, and prescribing attempts to put videogames on a level with literary and filmic experiences. Such resistance, always legitimate and undoubtedly necessary in a specific moment in game studies history, occurs especially in the ontological resource to ludology. The nature of this resistance is drawn not from an intentional opposition, but instead from the unintentional omission of the humanistic power - which this article considers a synonym of the narrative power - of the medium. As an example, the recent works by Juul (2013), Costikyan (2013) or De Koven (2013) represent an approach to videogames in their nature as a designed artefact, undertaking their arguments in terms of rules and mechanics or focusing on other types of purely formal aspects such as what is called the "art of failure" (Juul 2013) or the value of the "uncertainty" (Cosikyan 2013) of the ludic execution. Differences aside, it would be quite surprising if in the field of film studies there were a singular, never-ending debate regarding eyeline match and off-camera, i.e. concerning an essential part of cinema which, as such, cannot be renounced.

As far as we are aware, such opposition serves to highlight the unconscious subordination of any kind of ideology to the market, a common practice in the West that is prescribed by the capitalist system. Indeed, game studies was founded in 2001 from a purely formalist standpoint, with its foundational text written several years pre- 
viously (Aarseth 1997). The struggle to distinguish videogames from other expressive media is not only demonstrative of a legitimate academic position in the defence of this new medium's ontology; it is also a devastating victory for the capitalist system. After all, surely the birth of an expressive medium yielding tremendous profits and with universal reach is a capitalist triumph? Indeed, it is a medium geared exclusively towards entertainment, confined to its own form, distinct to any form of reality, and, in consequence, locked in a perpetually non-critical state. Moreover, is the articulation of a science in its name, ludology, not an even greater triumph for capitalism, exhausting itself in a perpetual reverberation of its own arguments over the course of the past decade?

It is no secret that there is an inextricable link between videogames and dystopia, the very antithesis of utopia, in which the alienation of man is depicted in a wide range of ways. Nonetheless, this association is not motivated by a critical spirit; instead, in such cases, dystopia is used as a fictional façade. As Schell notes (2014), videogames need to place characters in new contexts that can justify the player's learning of rules of the gameworld. Dystopia, despite having become a recalcitrant common space for modern fiction, grants this type of licence to the apocalypse, amnesia, or exile. In our view, there is a fundamental distinction between utopia and dystopia; as such, while utopia allows us to envisage situations that are beneficial to humankind, starting from the current state of man's place in society, dystopia has a tendency to disconnect from this same reality by representing stories with negative characteristics, unconsciously inciting us to embrace the virtues of the current system. Dystopia appears to enjoy its confinement to the realm of videogames' innocuous ideas; in contrast, utopia's exile should encourage us to value the present, unique force of the videogame medium as a centrifugal expressive form, and not as a simple centripetal entity. This is, of course, the objective of this article: to reflect on the capacity of videogames to spread theories of a better world from the inside out, starting with the world as it currently is and, if possible, distinguishing the causes of its successes or failures in this titanic task. Before delving deeper into our investigation, we must begin by highlighting one of the factors responsible for the present latency of utopia.

Capitalism constructed a never-ending range of possibilities based on money as quickly as it consumed our real capacity to make decisions about our own existence; to paraphrase Touraine (2001), we are extras with serious difficulty in becoming protagonists. As Jameson (2005) affirms, adapting that famous phrase uttered by Margaret Thatcher, there is no alternative to capitalism. Once the collapse of the socalled 'Second World' threw its woes into clear view, utopia - associated by some on the Western left with Soviet communism - lost all its previous potential and prestige. This defunct utopia gave rise to incalculable financial losses, millions of lives lost at the hands of totalitarian terror, and environmental degradation on an apocalyptic scale (Gray 2005). Following its failure, we have been left alone with capitalism. As such, only the new enemy of religious fundamentalism stands against Western imperialism, though it does not articulate an anti-capitalist thesis in doing so. This situation of mandatory imposition has been explained by Fisher via the notion of capitalist realism. The British-born writer and critic believes that there exists "the widespread sense that not only is capitalism the only viable political and economic system, but also that it is now impossible even to imagine a coherent alternative to it" $(2009,2)$.

The system reigns supreme, bolstered by armies of consumers who have confused the idea of progress with that of being on-trend. Man has deserted his capacity to imagine future worlds in which the notions of progress and wellbeing may once 
again possess a true meaning, the one which was passed down by the fathers of the Enlightenment or the proponents of UNESCO following the Second World War (Finkielkraut 1996). The roots of this desertion may well be found in the global imposition of the free market in accordance with the model of liberal Western democracies, an act that was difficult to replicate in countries such as China and Russia owing to the idiosyncrasies of their situations. The consequences have been as catastrophic as those of the false communist utopia, resulting in tens of millions of Chinese peasants being forced to become migrant labourers and millions of people being excluded from work in the more advanced societies (Gray 2005). In these countries, the materialisation of a global free market economy has not been accompanied by institutional development or the extension of Western values; in contrast, it has signalled the end of the epoch of global Western supremacy and the advent of a point-of-no-return for past levels of prosperity and social cohesion in the West (Gray 2005). Ultimately, free rein has been given to capitalism.

In this neoliberal and anarcho-capitalist epoch, the concepts of progress and wellbeing possess a purely material meaning brought about by the market's excessive presence in our lives - and this will continue to be the case owing to the unrelenting hypertrophy of capitalism as an economic system. Its cyclical nature, infinite in character, is based on the union of capital and its subsequent investment, with a desire to accumulate profits that are then re-invested (Boltanski and Chiapello 2002). It is no surprise that, in this context, utopias are met with indifference and astonishment. Today, they have been replaced by one supreme vocation: that of the machine wanting to possess everything by means of money. In capitalism, needs have been replaced by desires; such desires are not biological, but psychological - and, like capitalism, they are infinite. From a philosophical perspective, Deleuze and Guattari (1972) warned that we are all machines in capitalism, a terrible connective organism whose sole desire is production-produce, in which nature and man are one and the same non-differentiated entity because the distinction between them, which once defined our place in the world, has been absorbed by the activity of machines that desire or produce. Capitalism is a machine of infinite activity based on infinite desires; unfortunately, our capacity to generate utopias has been superseded by the belief that capitalism, in its execution of never-ending sequences, will itself result in a superior state of progress for humanity. This notion has eradicated the political capital of utopia, relegating it to the realms of fantasy and of science fiction.

It has been debated whether utopia pertains to the field of politics or literature; as Jameson (2005) notes, utopia as a genre has always been a political theme with a literary form. Today, in any case, it is a solely literary concern. This definitive displacement of the concept of utopia toward the cultural sphere, and its fusion with the genres of fantasy and science fiction, is demonstrative of two transcendental factors. Firstly, it shows the existence of a separation between the economic, political, and cultural spheres in capitalism. Bell (1996) affirms that in capitalist society, these three spheres are governed by contradictory principles, even if, historically, they were born from the same impulse. For example, the bourgeoisie and experimental art both expressed a mutual, unconditional rejection of each other, despite having both emerged from their rebellion against the past. In consequence, the principles that regulate these spheres are opposed; where the economic sphere is concerned with efficiency, the political sphere is concerned with the search for equality and the cultural sphere with self-gratification. It is not difficult to imagine that this triad of objectives would prove to be contradictory and result in a perpetual source of conflict in capitalist societies. In the past, it was possible to conceive a holistic definition of society, but this is 
no longer the case. These three realms, albeit distinct, can interact with each other but almost always act in accordance with exclusive norms. In consequence, and in the second instance, the present innocuousness of the utopian genre, now yet another member of the ineffable and extensive cultural network of our societies, is motivated by an exceptional fact. Indeed, though utopia (or any of the other illustrious members of the cultural sphere) can be used to critique aspects of the world associated with the other spheres, it cannot modify the future behaviour of said spheres. Marcuse (1968) noted how the unbridgeable gulf separating these three realms provides, on one hand, necessary perspective for the cultural sphere to act as a tool of critique and objection to any political or economic factors, yet, on the other, condemns all its interventions to be futile, relegating culture to a frivolous and trivialised space in which the intersections with other spheres are non-operational.

A reassessment of this classic argument by the Frankfurt School can be found in Jodi Dean's works, expressed concretely in her notion of communicative capitalism. The current situation, in which ideas and political content are circulated through means other than those offered by institutions, such as social networks or websites with syndicated content (RSS), proves a paradoxical inoperability in opposing the official political agenda and thus transforming the environing reality via citizen activism, using these new media as a support.

On the basis of the concept of communicative capitalism, Bulut, Mejia and McCarthy (2014) have analysed the online game Free Rice (developed by World Food Program, 2007-2018) under the critical perspective known as "the rise of the ludic sublime". Naturally, videogames are acclaimed in neoliberal societies as a plausible solution to complex political problems, forming part of the philintainment practices. Nevertheless, as stated by the authors, Free Rice depicts the abandonment of social problems by the states and recalibrates the value of citizen participation in technoconsumerist terms $(2014,347)$.

As Dean notes, the matters brought to the public debate by the counterhegemonic model, among which these kinds of games would be included, rarely find answers due to the abandonment by official institutions of this function, hiding behind the existence of this circulation of ideas:

Today, the circulation of content in the dense, intensive networks of global communications relieves top-level actors (corporate, institutional and governmental) from the obligation to respond. Rather than responding to messages sent by activists and critics, they counter with their own contributions to the circulating flow of communications, hoping that sufficient volume (whether in terms of number of contributions or the spectacular nature of a contribution) will give their contributions dominance or stickiness (Dean 2005, 53).

The most immediate consequence of this phenomenon is that it renders culture symbolic, that is, it places it in a metaphorical limbo that is disconnected from the real world. Hauser (1969) believed that artistic forms of a symbolic nature principally develop in capitalist societies, perhaps as a means of eluding any real critique of the system. However, it is no surprise that an emancipated critique of real issues flourishes in this context, an 'other-worldly' examination focused on the formal investigation of works or the ludic element concerning how the textual relations woven between them are established. Is this not a fundamental definition of videogames: a pure form so distinct from reality that it requires its own rules and emphasises its ludic nature? 
Coinciding with this social mitosis, Hauser (1969) also observed that since Romanticism; in other words, coinciding with the practice of economic liberalism, the symbolic fictions of culture and of art have become a means of compensating for the unlived, becoming valuable and meaningful for individuals who had been unable, or who had not known how, to make the most of their life's journey. A discrepancy between social function and aesthetic function is formed within us, transforming cultural or artistic works into a microcosm used as a refuge from our own life experience and, therefore, rendering it materially separate from this same reality. The exacerbated use of symbols in capitalist cultures - effectively a masking of reality - implicitly carries with it an escape towards a fictitious world. This idea of escape through fiction created by art or culture is an aesthetic possibility that is completely alien to a pre-Romantic conception of both of these realms. For Nietzsche, science was the source of nihilism as it provoked the destruction of unreflexive spontaneity in the world (Bell 1996). Today, we can assert that it was, after all, capitalism, without a doubt a concept that is in many aspects tied to science, which triggered a definitive separation between culture, politics, and economics and dealt the final blow to this irrational spontaneity. As a result, it is no surprise that utopia, relegated to the cultural sphere, has become a purely imaginary and fictional concept with no real transcendence nor any transformative capacity.

On one hand, utopia is incapable of affecting the political and economic realms, given that it pertains to the cultural sphere; on the other, the enunciation of its discourse, transmitted via artistic media such as literature, film, or videogames - featuring equally in this sphere - is geared towards the creation of fictitious worlds bearing the hallmarks of a refuge from this brave new neoliberal world that has been handed to us (Table 1).

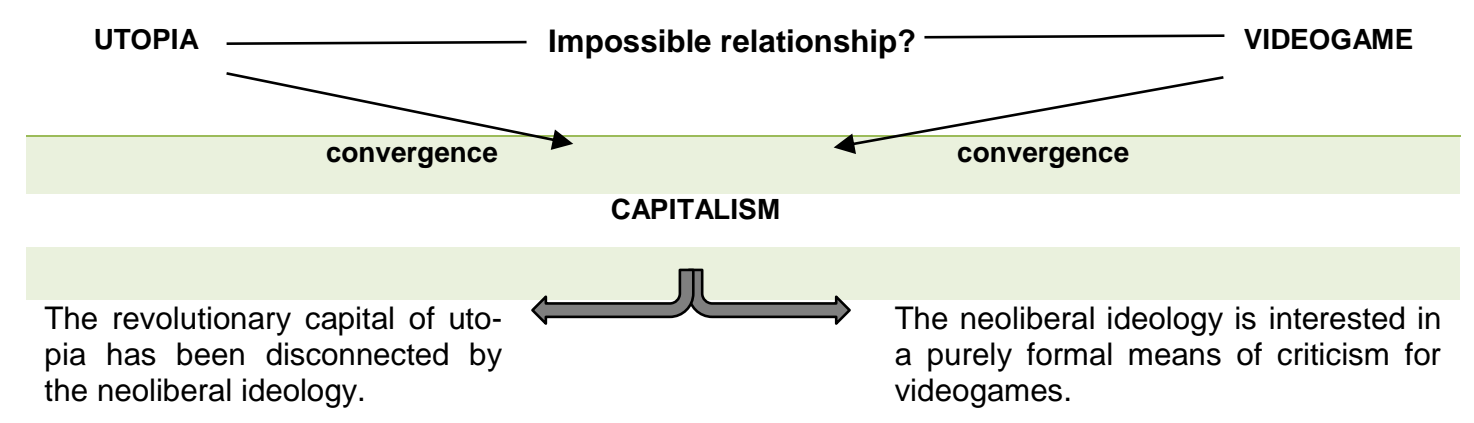

Table 1. Capitalism, utopia, and videogames.

Ultimately, at present, utopia is no longer characterised by its capacity to envisage or construct better worlds. In its new form, the notions of progress and of improving the conditions of our existence have been supplanted by the idea of going on a voyage the farthest flung and costlier the better. Bauman (2006b) describes an anecdote that cannot pass without mention: when you enter the word 'Utopia' into Google, the first entry that appears is a videogame. Far from being cause for satisfaction, this fact serves to demonstrate the widely-held opinion of videogames as a form of 'holiday retreat', refuge, or means of escape, while simultaneously emphasising utopia's impotency and, in so doing, relegating it to the mere role of a ludic, fictional framework.

However, not everything is bleak. The separation between these three spheres is regarded by other researchers not as a tragedy, but rather as an integral feature and cause of optimism. McGonigal (2011) proposes a fluid communication between eve- 
ryday reality and the reality established by videogames, to the point of underlining the influence of the latter on the former. In McGonigal's perspective, the key issue of the matter is discovering whether the principles of compromise and reward, essential in the design of any quality videogame, can function in a similarly efficient manner in problem-solving situations in the real world. The answer is strongly affirmative: "Gamers who have grown up being intensely engaged by well-designed virtual environments are hungry for better forms of engagement in their real lives" $(2011,245)$. Far from maintaining that there exists a trivial space for culture, McGonigal states that players are a natural source of participation in citizen journalism projects, collective intelligence or humanitarian actions. Proving this phenomenon to be an unstoppable and growing process, McGonigal speculates that the era of crowdsourcing videogames will spur the masses to social mobilisation with the aim of solving real world problems in the same manner as in the ludic context of virtual worlds $(2011,246)$.

\section{Case and Methods}

In this bleak context, can videogames bring new life to utopia? This would appear to be a difficult task. Videogames are a medium erected in the image and appearance of capitalism: they simulate the remunerative essence of the system when placing us in the role of an avatar that spends money or that receives payment for his or her work (Dyer-Witheford and De Peuter 2012). Moreover, videogames obliterate the idea of realistic, human worlds that are tied to reality. It is no surprise that the worlds generated by videogames always appear alien to us, especially in the most successful games or those received most favourably by the public. Videogames become locked into the complex symbolism highlighted by Hauser (1969), trapped within themselves and revealed to be unabashedly cloaked with an enticing 'other-worldly' nature. Videogames' strength as a refuge rests in the fact that they are detached from the everyday, yet this is also the source of their weakness as an expressive form of social vocation. The medium's power to create and change the world was stripped away at its inception, as it was instilled with the ideology of its creators, who were essentially engineers and programmers fascinated by unreal worlds (Anthropy 2012). Indeed, owing to their mastery of information technology, these pioneers' transformative abilities became a simile for the role of magic in fictional universes, an ostensibly innocuous fact that forced the medium into exile in the realm of fantasy.

Conversely, the centripetal formalism that is characteristic of the medium is tied to an ideological evolution where, owing to a sentence once again handed down by the economic system, our way of relating ourselves to the world abandoned the domain of 'knowing' in favour of 'processing'. Videogames synthesise this cultural transformation in the extranoematic effort required by players during gameplay or in the games' configuration based on menus. It is easy to identify any number of human activities which, in this new 'processing' culture, promote the use of configurative systems based on interfaces akin to those used in videogames. Such acts of configuration are indispensable in our daily lives, as much with work as with leisure (Galloway 2006). Likewise, it is no coincidence that many of the processes and routines that we carry out in different contexts of our daily lives bear a resemblance to videogames. As we will see below, the first serious attempt to connect the medium with the utopian genre rests squarely in the so-called procedural rhetoric of videogames.

The existing problematic relationship between work and leisure in modern societies has been thoroughly examined in the scope of game studies. From a strictly ideological perspective, it appears that the fade of its dividing line is a victory for the current cultural theory. In our opinion, though, it is misleading to consider this a tri- 
umph. As Eagleton observes $(2003,16)$, traditional academism has ignored the daily lives of common people for centuries. Nowadays, however, we can observe within academia the synthesis of these formerly irreconcilable instances in a gapless continuity between intellect, work and daily life. According to market demands, leisure activities are reintegrated and mixed with labour activities, thus invalidating the puritan, secular dogma that establishes that work and play are two different matters. Once again, the elimination of this boundary has helped the capitalist economic system and especially the industrial sector of videogames, where most of the current fans are eager to work voluntarily to fulfil their entirely emotional and nostalgic wishes. Thus, this new paradox in the system gives meaning to studies by authors such as Kücklich (2005), Wark (2006), Lund (2014) or Bulut (2015).

Kücklich employs the concept of playbour, a blended word composed of the lexemes 'play' and 'labour', to re-evaluate the relationship between play and labour in modding (computer game modification), where its precariousness "as a form of unpaid labour is veiled by the perception of modding as a leisure activity, or simply as an extension of play" $(2005,1)$. Kücklich tries to clarify the changing relationship between work and play in the present era, as well as study its ideological ramifications.

Likewise, we consider the relationship proposed by Wark (2006) to be substantial; that is, the relationship between the perfection assigned to videogames and the imperfection of the gamespace, the latter being a result of the changes that the free market forced into daily life. The gamespace would be an ideal place for a new figure to appear: that of the player, transformed into the logical nexus of both communicational realities:

Here is the guiding principle of a future utopia, now long past: "To each according to his needs; from each according to his abilities." In gamespace, what do we have? An atopia, a placeless, senseless realm where quite a different maxim rules: "From each according to their abilities - to each a rank and score." Needs no longer enter into it. Not even desire matters. Uncritical gamers do not win what they desire; they desire what they win (2006, 14-15).

The latest research by Lund and Bulut is focused on the framework established by the writers mentioned earlier, while simultaneously adding to said framework. Lund argues that an analysis-based model on the notion of playbour "will help me to analyse and criticise the contemporary use of the term" $(2014,735)$, whereas Bulut introduces the fitting concept of "Degradation of fun" to highlight the way in which "testers' passion about video games is contested vis-à-vis the hegemony of precarity in the profession" $(2015,241)$.

In spite of the ominous panorama highlighted above, it is possible to specify at least two moments in the history of videogames associated with utopia; by describing and analysing both of these moments, we will be able to conclude whether these associations are effective. When forming these two categories, specific videogames with some utopian aspirations but which do not, in themselves, conform to one of the trends have been omitted (Table 2). 


\begin{tabular}{l|c|c}
\hline \multicolumn{2}{c}{ MOMENT 1 } & MOMENT 2 \\
\hline Genre & Procedural rhetoric & Walking simulator \\
Date & 2003 (September 12th) & 2009 (The Graveyard) \\
Expression & Simulation / Formalism & Simulation / Narrativism \\
Connection with utopia & No utopia & Diffident utopia \\
Public reception & Minor & Massive
\end{tabular}

Table 2. Videogame moments associated with the utopian genre.

As noted previously, it was paradoxically at the very heart of the formalism derived from the capitalist imprint on the medium that the first attempt to connect games with aspects of real life emerged. This school of thought, to which many 'serious games' pertain, is called 'procedural rhetoric'. It offers an interesting theory of the expressive power of videogames by using a rhetoric pertaining to the medium itself, erected on the basic processes derived from its technological nature. In this sense, we can say that this is a style rather than a generic category, as a result of which it is susceptible to appearing in a wide range of games. It was thought that this special capacity of videogames was sufficient for their achieving a connection with a diverse range of human issues. Conversely, a decade after the birth of this first attempt, a new discussion emerged with unexpected momentum concerning the medium's capacity to connect with reality. This phenomenon was associated with a growing number of videogames deemed to be actively political purely because they drew away from the ludus that is bound to characterise them in formal, structural, and ludological terms. This debate involves so-called 'walking simulators', a label that refers both to a generic category and to a style. Understandably, the propensity of such games to human issues diminishes the significance of their form - resulting in fewer rules and mechanics - and increases their narrative value - resulting in a more emotional slant to their plots. As we will see, these games have sparked a debate concerning the limits of what does and does not constitute a videogame, and have led to their association with the moniker 'social justice warriors', a pejorative designation intended to highlight the superficial treatment of some of the ideas they espouse.

\section{Two Videogame Moments Associated with Utopia}

It is important that our choice of two particular moments in videogames associated with utopia be clarified. The first moment, focused solely on analysing videogames of procedural rhetoric, should be understood within the context of this article as the epitome of all practices - ludic, procedural or otherwise, and hermeneutic - that we believe to be unsatisfactory in trying to show and analyse the videoludic medium as an ideological weapon capable of revolutionising the strong and reigning neoliberal system. As will be shown, assuming this impossibility leads to the second moment: the relationship between walking simulators and a utopian stance that we have designated as diffident. This is possibly the only true way towards achieving a utopian construction in videogames.

Despite this decision, it would be unfair not to acknowledge other writers' invaluable efforts in recovering, defining and tagging a certain ludic praxis as an act of dissi- 
dence against the Institutional Mode of Representation and therefore a fitting one to convey the utopia understood as an alternative to capitalism. Galloway and his concept of "countergaming" (2006) or Dyer-Witheford and De Peuter and their notion of "games of multitude" (2010), are good examples of this. In fact, we cannot ignore the way in which certain ideas of "games of multitude" are in clear opposition with our main thesis of a videogame apart from reality. Unfortunately, it is also important to acknowledge that many of the means proposed by these authors do not lead to a real electrolysis of the neoliberal system, due to those means being in the minority and distanced from the mainstream. Labels such as 'marginal' or 'peripheral' contribute both to their definition and to the limitations in their groundbreaking nature. In capitalist society, using labels to define a phenomenon means that the system has managed to absorb it. However, the comparisons of some of these ludic paths with those followed by other means of expression like cinema or Godard's "countercinema" (Galloway 2006, 109) are not very useful. We believe that this search for similarities further highlights the incapability of videogames to change their destiny. It is important to remember that the Nouvelle Vague movement established a mode of representation different from that of the institutions - the Modern Mode of Representation, with its roots in neorealism in the Second World War - and its critical project reconstructed the historical sense of cinema. Are videogames or any other critical project established in their name prepared to undertake such a task? It is possible that the only hope lies in the paths known as "counterplay" and "dissonant development", outlined by Dyer-Witheford and De Peuter and understood as "acts of contestation within and against the ideologies of individual games of Empire" (2010). The system can only be undone from the inside.

\subsection{Are Games with Procedural Rhetoric a Useful Vehicle for Utopian Ideas?}

The key question that predominates in this type of videoludic discourse is: what problems can videogames bring to light? One of the genres that is best suited to this social initiative are so-called 'newsgames', which have an informative purpose tied to current affairs and which originated with the game September 12 ${ }^{\text {th }}$ (Frasca 2003). Broadly speaking, these games have resulted in other ludic practices designed to raise public awareness about topics such as citizens' rights and responsibilities, the denunciation of situations of injustice, or educational and environmental proposals. Many of these 'serious games' use procedural rhetoric, accentuating the principle of simulation specific to videogames and conferring maximum freedom to the designer to create a meaning for the game. Nonetheless, this level of control does not ensure that a correct meaning about the simulated reality will be generated. As such, our principal objective is to question the procedural pathway's capacity, as a form of game design, to achieve a plausible approximation to utopia.

Drawing from the definition of the essential properties of digital artefacts espoused by Murray (1999), Bogost reveals how videogames function by executing a series of rules (2007). This proceduralism is not a practice exclusive to computers; human societies put a multitude of institutional processes into play. In consequence, procedural rhetoric is the ideal means of revealing how any process works by simply adjusting the logic of real systems - based on processes - to the internal and procedural logic of the programming languages upon which videogames are based. In consequence, procedural rhetoric offers a new way of making statements about how the processes governing human activity function.

Bogost describes the role of the player in the logic of a procedural rhetoric videogame by using the simile of a truncated syllogism or enthymeme. A truncated syllo- 
gism is one that avoids one of its premises purely because its absence does not stop the syllogism from being understood. As such, the syllogism 'Socrates is a man, Socrates is mortal' elides the main premise or general rule that 'All men are mortal' because this is obvious or, in other words, because it is the receiver's responsibility to reach this conclusion. In the case of videogames, it is the designer's task to hide the message so that it can be revealed by the player when playing the game. In both cases, for the simulation to be produced with guaranteed success, the game must overcome what Bogost coins "simulation fever". The culture of simulation has given rise to certain reactions to simulated works: on one hand, 'simulation resignation' supposes a blind acceptance of any simulation, even one that is defective; on the other, 'simulation denial' is the rejection of a simulation on the basis of it being a replica (Turkle 1997). The true value of simulation emerges when these reactions are overcome: "A simulation is the gap between the rule-based representation of a source system and a user's subjectivity" (Bogost 2007, 107).

In order to reveal some of the contradictions of proceduralism, we will proceed to analyse a procedural game geared towards understanding certain social, economic, and political processes that keep countries in the so-called developing world in a currently irrevocable position of inferiority. $3^{\text {rd }}$ World Farmer (Hermund et al. 2008) is a game that demonstrates the difficulty of generating a stable, profitable means of agriculture in African countries. What are the problems this game reveals - and, above all, does it really shed light on obscure areas whose revelation will allow for change and progress in these countries? Finally - and an essential question as it is a regulating idea in proceduralism - which contradictions in the real system, that is, of African agriculture, does this game expose?

Developed by a group at the IT-University of Copenhagen, the game begins with the slogan 'a simulation to make you think', and its main premise is managing a farm run by an African family. The difficulties the player is faced with are based on chance and on the political, economic, social, and natural circumstances that shape the destiny of the family's crops. As such, the success of a crop that is essential to the family's survival not only depends on the appropriate or inadequate distribution of resources - different crops, farm animals, farming tools - but is also affected by numerous variables of a negative complexion, such as wars, political changes, and natural disasters, that almost always conclude in the death of one of the family members or, worse still, its entire disappearance. The game is organised into turns that simulate the duration of a crop, in which the decisions made by the player - lawful or illicit, good or bad - are seen to be disrupted by these uncontrollable negative variables. Other decisions, such as sending the children to learn at school, simultaneously entail a considerable financial toll and reduce the family unit's work capacity, accentuating how fragile the family is and effectively condemning it to extinction.

So, does $3^{\text {rd }}$ World Farmer really make us think? Let us consider this point in greater detail. Firstly, and following the proceduralist maxim of the enthymeme, the syllogism that allows for the videogame to be understood is portrayed in Table 3.

Rule - African farming families are unable to develop a stable and profitable form of farming because political events, wars, and natural disasters in Africa impede this.

Case - The Ndongos are an African farming family.

Result - The Ndongos will never be able to develop a stable and profitable form of farming because political events, wars, and natural disasters in Africa impede this.

Table 3. Syllogism in 3rd World Farmer. 
The syllogism appears to be truncated in the game owing to the absence of its general rule: it is in the act of playing that the player is able to understand this rule, that is, the gloomy revelation that, in Africa, it is impossible to generate a stable economic system based on agriculture - a fact that would surely already be common knowledge for a player who is interested in the mass media's political agenda in the 'First World'. The omitted general rule is the effective presence of a dominant ideology that has imposed an inexorable sentence on these countries, an ironclad law that stops the player from considering other possibilities that are not contemplated by this law.

What we learn and think about as players of a procedural rhetoric videogame such as $3^{\text {rd }}$ World Farmer is not distinct from what we already know as members of a specific ideology that looks on Africa with a certain degree of scepticism. As such, the game itself stigmatises an entire geographical zone that is as large as its problems are varied, adopting the historical and Eurocentric judgement of African unity and, if this were not enough, equating the label 'Third World' with the realities of the African continent. To consider its nature in greater detail, perhaps we can assume that all the problems in the underdeveloped world relate solely to agriculture and that they are all represented in this game? The response can only be in the negative, and the subjective distance between the simulation and the simulated reality is too vast for us to suspend our disbelief. Conversely, the type of thinking generated in the player during the act of playing moves within the reassuring realm of deduction (Vargas-Iglesias 2018), where the framework erected by this general, described rule impedes the emergence of any form of creative or conjectural thinking that may allow for the simulated reality to be modified. We consider ourselves to be incapable - as is also the case for our family in the game - of contemplating other possibilities that could help us find solutions to the problems that are identified. What, then, is the purpose of a game that reaffirms and highlights an ideology without proposing any kind of investigation that could alleviate, modify, or transform the situation in question? The videogame is revealed to be both futile and dependent on a complex real experience that acts as a burden from which it cannot extricate itself: it is in this same burden that its meaning lies. The relationship that the videogame upholds with its simulated reality is that of an incomplete object owing its comprehension to a reality structured around hundreds of variables that it cannot entirely simulate and, worse still, that it is unable to modify. Both simulation and simulated reality share the same general rule that precludes individuals and governments from finding creative solutions to the problems faced by these countries. Indeed, it is this shared factor that plunges us into the true dilemma of procedural rhetoric games: their incapacity to generate an appropriate poetics of meaning and significance.

\subsubsection{Results and Conclusions}

Our critique of proceduralism is comprised of two fundamental ideas, converging in a crisis concerning this pathway's ability to act as a vehicle for utopia with guaranteed success. In the first instance, what is the purpose of a game whose meaning effectively rests in the process being simulated, rather than in the simulation itself? Effectively, the simulation of a real process via the procedural rhetoric of a game can be perceived to be an intertextual correspondence where, on most occasions, the significance of the game exists outside itself, that is, in a specific ideology that keeps the game in a relationship of servitude. Consequently, in the second instance, procedural games do not transmit new or conjectural ideas, but are instead blinded by a specific ideological perspective that ultimately comes to define them. Therefore, if procedural 
rhetoric always acts at the behest of an ideology, it follows that it rarely serves to generate new solutions to the issues that are presented. This is the case because, in terms of their constitution, these games are based on deductive cognitive processes that refute the abductive nature of videogames (Navarrete-Cardero et al. 2014).

The heuristic incapacity of procedural games is a consequence of their strictly formalist structure; as such, they must be judged according to structuralist criteria. Genette (1997) alludes to the classic distinction introduced by Michael Riffaterre in the relationships that texts uphold with meaning and significance. To summarise, Riffaterre shows how all texts have their own meaning; that is, they have a specific interpretation, but they do not control its significance. In order to access a poetics of significance, works must transcend their limits and reveal the connections they maintain with other texts - or other realities - in textual or relative terms; it is only in this way that we can know the genre to which a work pertains, the genealogy of its structure, or why its protagonists are constituted in a certain way. It is, of course, here where the procedural proposal fails to produce serious videogames associated with utopia. Let us imagine the following cases:

A. A procedural videogame is well designed and the player is unaware of the simulated reality. In this case, the player can access the realm of meaning, that is, a specific interpretation of the game, but not the game's significance. The pretence that a player can access the realm of significance - that is, that they can grasp the simulated reality because of the game - is to think of learning as a simple process of content absorption: "Picture that sequence from The Matrix where Neo has new skills downloaded directly into his head and can use them instantly" (Jenkins et al. 2009, 448). In our opinion, it is only in a serious game that seeks to inform the player about something they are unaware of - an omitted general rule that they are required to deduce - that a satisfactory simulated experience is plausible. However, even in this case, though the game would succeed in achieving a certain degree of utility, we must recognise that it would only do so because of the player's lack of knowledge about the simulated reality. As such, how can the player calibrate the utility of an experience that is forged in absentia of their knowledge of said reality? Are they expected to blindly trust a message accessed by deductive means that reveals the dominant ideology?

B. A procedural videogame is poorly designed and the player is aware of the simulated reality. In this case, owing to the incorrect implementation of the mechanics or another kind of imbalance, the game generates a meaning that does not reside in the game itself, but which surfaces solely because of the player's knowledge of the simulated reality. The impossible suspension of disbelief, that is, the appearance of simulation denial, annuls any contract of significance between game and simulated reality. Instead, such a situation results in a pointless game based on a deductive type of thinking, where only knowledge of the general rule - in the form of an enthymeme of the game - justifies the game's meaning, underlying its scant heuristic value and negating any expansive type of knowledge concerning the simulated reality.

C. A procedural videogame is well designed and the player is aware of the simulated reality. In this case, the videogame generates its own meaning and accesses the realm of significance, connecting with the simulated reality in a pertinent manner via simulation resignation. This would be an ideal situation were it not for its deductive structure, which, as in the previous case, will never give rise to a new perspective on that reality. As such, the heuristic value of this pathway is trivial and only serves to emphasise a predetermined ideological framework. Moreover, if we consider the affinity between the ideology of the player and the ideology of the game, 
new dissonances are created both in the realm of meaning and in the realm of significance. For example, in this case's ideal situation, can we speak of the emergence of significance if the player's ideology does not coincide with the ideology of the game? Would all the connections geared towards the constitution of significance not shortcircuit in the case of an ideological clash? In such a situation, would the player not reject the simulation owing to subjective impertinence, resulting in a situation similar to the one we are exposed to by a poorly designed game? And even if we were to imagine a situation where there was an ideological meeting of minds, what purpose would a game celebrating a specific ideology serve if this ideology were not discussed or interrogated?

D. A procedural videogame is poorly designed and the player is not aware of the simulated reality. In this case, the videogame does not generate a meaning, nor does it access the realm of significance.

\subsection{A Fluid Game: Are Walking Simulators a Useful Vehicle for Utopian Ideas?}

The term 'walking simulator' has its origins in the early 2000s, with strictly negative connotations. However, these connotations eventually disappeared, thus demonstrating the creative possibilities of this new ludic genre. Although this positive reframing of its meaning in gamer culture still has no influence in academia, it is possible to find it in specialised journalistic criticism, more focused on detecting fluctuations in the player's taste and choice (Clark 2017; Muriel 2017; Ortega 2017). Evidence of this conceptual revitalisation can be found on platforms like Steam, GamersGate or Itch.io, where games bearing this tag can be searched without any negative connotation attached to them.

The origin of this genre is possibly found in the 2003 proposal of artist and author Mary Flanagan, Domestic. "[Domestic] uses a software engine normally used to generate violent first-shooter video games in order to reconstruct a remembered childhood space where a dramatic event has taken place: a house fire" (Flanagan 2003). In recent years, examples of this type of games have increased exponentially, not only as a commercial strategy to reach a broader and more casual audience, but also as a relatively easy and inexpensive means for independent studios to access game development.

In the field of specialised criticism, walking simulators have revitalised the old debate, perhaps also noticeable in this article, between ludologists and narratologists. Bogost sets an example of this trend when commenting on Dear Esther (The Chinese Room, 2008), Gone Home (Fullbright, 2013) and, especially, What Remains of Edith Finch (Giant Sparrow, 2017):

What are games good for, then? Players and creators have been mistaken in merely hoping that they might someday share the stage with books, films, and television, let alone to unseat them. To use games to tell stories is a fine goal, I suppose, but it's also an unambitious one. Games are not a new, interactive medium for stories. Instead, games are the aesthetic form of everyday objects. Of ordinary life. Take a ball and a field: you get soccer. Take property-based wealth and the Depression: you get Monopoly. Take patterns of four contiguous squares and gravity: you get Tetris. Take ray tracing and reverse it to track projectiles: you get Doom. Games show players the unseen uses of ordinary materials (Bogost 2017). 
Nevertheless, in our opinion, Bogost forgets the fact that there are three different and concomitant dispositions in What Remains of Edith Finch, though not exclusive to the genre and shared across many other games: the hunter's gene, the scopic drive of the flâneur, and the investigator's thirst for knowledge. It can be argued that, aside from the clear relationship that these activities have with the ludic sphere, these three dispositions have the same principle: searching for a way to control the surrounding reality, an attitude that can be inferred from the nature of fluid games and their relation with the utopic genre of walking simulators. The player has inherited the spectator's wish of seeing it all, now enhanced by their ability to eavesdrop, examine and touch many places of the setting. The key difference, and not a trivial one by any means, between the Baudelairean flânerie and the motion of the wandering player in walking simulators is manifested in the role of presence in capitalist modernity, as pointed out by Benjamin. Thus, to Baudelaire, Poe or Benjamin years later, the wanderer is a man of the crowd (Benjamin 1972). On the other hand, the man who wanders in walking simulators is a solitary man, a searcher of signals and traces. Our interest in this genre lies in this search.

As stated in Section 2 of this article, the current dominant ideology, based on an economic system that is immune to any form of attack, renders all actions destined to modify specific realities ineffective. Videogames based on procedural rhetoric are destined to fail owing to their lack of practical utility. If a lesson can be learned from the inefficacy of procedural games, it is fact of the impassable divide between the inflexible processes of our society and any agenda or stratagem geared towards modifying their status. The present general order and its underlying processes do not allow for options: there is no clear route to utopia. As Bauman notes: "[...] it is far from clear what such options could be, and even less clear how an ostensibly viable option could be made real in the unlikely case of social life being able to conceive it and gestate" $(2006 a, 5)$. The systemic critique of contradictions in the processes of capitalist society is shown to be futile because the power to modify them has been liquidated by the new, inflexible, and immutable order of neoliberalism. A videogame geared towards exposing the contradictions of certain processes in our reality purely to show them to us - given that they possess no capacity to eradicate them - thus becomes the most accurate symbol for the new human condition.

What is this new human condition? Using Bauman's terminology, procedural rhetoric games have been geared towards the impossible objective of modifying the most solid order that has ever existed, one established by an economic system that has thrown off all the remnant shackles of previous orders by melting its 'solids'. All the political or moral powers capable of combating or reforming this new order have been destroyed or rendered too weak for the task (2006a, 4). The present system's solidity cannot be modified by a political agenda because this same system has dissolved the previously-existing nexus between individual choices and collective projects. Indeed, due to deregulation, liberalisation, market flexibility, and the fluidity of the labour and real estate markets, the system's strength is rooted in a total freedom of human agents, facilitating an absence of cooperation between these agents - that is, us - and the system. Instead of bending to us, this system appears to elude us $(2006 a, 5)$. In consequence, for the first time since the dawn of modernity, the construction of rules, customs, or norms for the success or failure of our existence is not incumbent on the system: it is a responsibility that has expressly fallen onto the shoulders of every individual. This new condition of man, defined as 'liquid modernity', is characterised by its malleability and the notable effort exerted by individuals to endow it with an almost-always transient form of stability (2006a, 8). 
In this new, liquid dimension of modernity, people have abandoned their dream of modifying systemic processes upon which they exert no influence. They conform and are simultaneously forced to turn within themselves, with an urge to transform the search for stability into their sole life's project. With the possibilities for building a new, better order extinguished, a forced internalisation of utopia is produced, motivated solely by a desire to generate a favourable personal world in an unfavourable context. This internal search has its correlate in a type of videogame that is less ambitious than procedural games, dedicated to narrating - yes, narrating - our small place in the world. The current incarnation of this type of game is the walking simulator, a fluid videoludic discourse that renounces the utopia of impossible global change to instead focus on the infinitely small aspects of our daily lives, identifying the emotions experienced within them, highlighting their successes and failures, and intending to supply our lives with the stability that we crave (Table 4).

\begin{tabular}{|c|c|c|c|}
\hline WALKING SIMULATOR & DEVELOPER & DATE & THEME / UTOPIA \\
\hline The Graveyard & [Tale of Tales] & 2008 & Old age \\
\hline Dear Esther & $\begin{array}{l}\text { [The Chinese } \\
\text { Room] }\end{array}$ & 2008 & Existentialism \\
\hline That Dragon, Cancer & $\begin{array}{l}\text { [Numinous } \\
\text { Games] }\end{array}$ & 2016 & Cancer \\
\hline Firewatch & [Campo Santo] & 2016 & Break-up \\
\hline Everybody's Gone to the Rapture & $\begin{array}{l}\text { [The Chinese } \\
\text { Room] }\end{array}$ & 2016 & Apocalypse \\
\hline Fragments of Him & [Sassybot] & 2016 & Homosexuality \\
\hline Kona & [Parabole] & 2017 & Terrorism \\
\hline What Remains of Edith Finch & [Giant Sparrow] & 2017 & Family \\
\hline Hellblade: Senua's Sacrifice & [Ninja Theory] & 2017 & Psychosis \\
\hline
\end{tabular}

Table 4. Fluid videogames: walking simulators and utopia.

It is no coincidence that these games have emerged within a community of independent developers, just as it is that games in this pathway construct - in a purely humanist sense - a space dedicated to reflection. We classify this utopia as 'diffident', that is, a utopia that is timid, fearful, and fainthearted if we compare it with genuine utopian vehemence. Perhaps it is this utopian diffidence, present in many walking simulators, that has led many videogame critics to associate these games negatively with the label 'social justice warrior':

A pejorative term for an individual who repeatedly and vehemently engages in arguments on social justice on the Internet, often in a shallow or not wellthought-out way, for the purpose of raising their own personal reputation (Urban Dictionary 2017). 
It is, of course, true that some of these videogames use sensitive social themes as a mere ludonarrative context, rarely proposing solutions to them or reflecting on them. Such games use these topics as a superficial plot device without answering the questions that they inevitably elicit in the player. Nonetheless, we believe that to extrapolate this behaviour to all fluid videogames is an act that is as small-minded as the excessive and unjustified praise that is sometimes lavished upon them. This dualist critical perspective of walking simulators, fluctuating between panning and flattery, has stretched the debate to other elements such as their artistic capacity, their ludic nature, or their social commitment:

These types of games are beloved by Feminist Frequency types who hail them as brilliant alternatives to the "male power fantasy" inherent in most big budget violent games. Many jaded, liberal, gen-X reviewers inflate the scores of these titles, saying these are finally games made for "adults," and chiding the wider industry for its perceived immaturity (Hicks 2016)

[...] story-focused games [are] more like films than games, goes the usual critique, and games are supposed to be games. Worse, these games often tackle themes like race, class, identity, and so forth, inevitably offering up some sort of progressive message - they're political, which is just about the worst and most annoying thing a video game can be (Singal 2016)

Yet, paradoxically, these games prove to be extremely enriching in a personal sense when they root us in existential universes, put us face-to-face with cancer, or give us a closer insight into psychosis. These games humanise the medium of videogames, tie them to reality, and invite us to empathise with situations that we may not have experienced. Despite this enormous power, they are accused of not being authentic games due to the lack of actions available during gameplay. Indeed, the actions in a walking simulator do not occur 'from the top down', which is the usual framework for actions that can be performed in a traditional videogame; instead, this type of game attempts to simulate actions 'from the bottom up', a decision that distances it from the pure ludus and from a strictly ergodic goal and draws it closer to abstract objectives that are often purely emotional. Is this relocation of actions a sufficient reason to expel walking simulators from our videoludic paradise? (Table 5).

VIDEOGAME

Traditional videogame

Walking simulator

\section{ACTIONS}

Jump, run, shoot, catch, throw, hit, etc.

Feel, cry, scrutinise, empathise, etc.

Table 5. Actions in traditional videogames and fluid videogames.

The characteristics of fluid videogames can be seen in any walking simulator. In order to demonstrate some of their qualities, we will focus on a game from the latest generation that has an ambiguous, hybrid nature. Indeed, Hellblade: Senua's Sacrifice (Ninja Theory 2017) intersperses a realistic and human complexion with the façade, and certain ludic hallmarks, of a triple-A title. This game boasts an enthralling plot concerning the protagonist's psychosis, and a bipolar form of gameplay that oscillates between a prototypical walking simulator and a 'hack-and-slash'. The latter aspect reveals a hidden tension in the player derived from their preference either for 
Senua's story, concerning the psychotic process and the game's walking simulator nature, or for the moments when the protagonist has to fight, a remnant of its hackand-slash origins that entails a break from the narrative discourse by obliging us to take up the sword and act in classic ludic fashion. This strange case of 'Dr. Walking Simulator' and 'Mr. Hack-and-slash' can be summarised as shown in Table 6.

HYBRID NATURE OF HELLBLADE

\begin{tabular}{ccc} 
& MECHANICS & GAMEPLAY \\
\hline Traditional videogame & Fighting & Plot digression \\
Walking simulator & Emotional value & Plot progression
\end{tabular}

Table 6. Fusion of fluid videogame and triple-A title.

The player's ludic reality is nothing other than Senua's psychotic crisis, produced by her shock at the death of her loved one. Through her heroic quest, transformed into our ludic experience, the player is able to discover the possible genesis of Senua's psychosis, her relationship with her evil father, and the significance of the absence of her mother. Perhaps our adventure is no more than a hallucination produced by Senua's tormented mind, or maybe the struggle against darkness takes place only in her psyche.

\subsubsection{Results and Conclusions}

Does Hellblade break any new ground with regard to psychosis? In the game's narrative, there is evidence that rigorous research about the disorder was undertaken, a fact that is subsequently emphasised in the execution of its visual, acoustic, and ludic components. As such, the voices heard by Senua or the puzzles resolved by the player during the game are closely tied to the symptoms, hallucinations, and delirium caused by this illness. It is clear that the way psychosis is dealt with in the game draws on the advice of health specialists and people experienced in working with individuals suffering from the disorder, as Ninja Theory has itself noted in a selfproduced documentary. As a result, the game's main virtue is the discovery of psychosis by those who know nothing about it and who do not have to live with its harsh realities. Senua's ludic incursion into an increasingly dark world is the figurative antithesis of the path to knowledge pursued by the player vis-à-vis this mental illness. Is this fact sufficient for recognising this game's social validity? Does the game help to construct a better world in the terms defined earlier in this article? Does it merely use psychosis as a means of constructing a lifelike character, or are there philanthropic interests at play? In our opinion, what is most important is not the content of these queries, but instead the very possibility of articulating them in a mass-market videogame.

\section{Discussion and General Conclusions}

This article aspires to provide answers to two questions: the first asks if it is possible to identify a link between utopia and videogames; the second focuses on the possibility of transcending the formalism of ludology and thus the cybernetic groundwork found in the neoliberal paradigm of control.

The identification of two historically significative forms in which both concepts have built their relationship (rhetorical procedure and walking simulators) has been 
useful to answer affirmatively to the first question, although the appeal of the first case to the enthymeme and thus to narrow and preconceived discourse differs from the humanist performance of the second case. Regarding the second question, as a consequence of an analysis of the said difference, a utopian potency which transcends the formal limitations of proceduralism has been found in walking simulators. This videoludic formula inaugurates what we term a 'diffident utopia', consisting of an intimist version of the old utopia in that it is based on microprocessual dynamics that, by means of being based on a certain ethics of care, moderate the medium by making it stray away from 'strong' structural logics. This helps this formula to become the most solid candidate to the expression of utopia according to the options suggested by the cybertextual logics of videogames.

These conclusions suggest certain questions. On one hand, the exclusive association of two moments in videogames with utopia - procedural rhetoric and walking simulators - at the expense of other analytical possibilities is both a risk that researchers are to take and a way of saving effort. Clearly, this decision does not exclude other possibilities, as new relations between the utopic genre and other videoludic genres and styles can be found. As such, we assume the successes of this decision, but we also assume responsibility for its shortcomings. We have considered that these two methods are the most logical ones with which to undertake an initial approach to the videogame's relationship to utopia, and we are also willing to admit that they might be guided by a criterion of obviousness: the high amount of political content of most of the procedural games and the deep influence of moral compromise in many walking simulators made us choose this path, clear and expeditious to us. Likewise, we do not believe that it is necessary for there to be a definite utopic intentionality in the creation of these games. As suggested by Deleuze $(1968,125)$, Eco (1979), and Foucault (1969), the work, once abandoned by its creator, stands on its own, and thus the researcher has the responsibility to determine its social function and grant it critical value via the rules of academic debate.

From a quantitative perspective, the affirmations in this article related to procedural rhetoric games are based on a case study of very limited scope. This fact, otherwise conscious, lies in the certainty that both the structure of procedural rhetoric games and their ideological nexus with simulated reality remain intact in any game designed according to its principles. Although they are not directly referenced in this article, many other games were taken into account when exploring the shortcomings of this ludic typology in relation to its capability of creating plausible solutions to real problems that can connect it with the creation of utopias. For instance, the games by La Molleindustria - from McDonald's Video Game (2006) to To Build A Better Mousetrap (2014) and Nova Alea (2016) - cannot escape the formalism and the logic of their structure per se, since they are based on an enthymemic scheme. Therein lies the greatness and the hardship of these games: they can denounce dissonant processes in our society, but they must always do it under a specific ideology they serve, whether akin or opposed to ours, that is eventually established as a premise or main rule of its syllogistic base. 


\section{Deduction:}

Rule- All men are mortal Case- Socrates is a man Result- Socrates is mortal Induction:

Case- Socrates is a man Result- Socrates is mortal Rule- All men are mortal

Abduction:

Rule- All men are mortal

Result- Socrates is mortal

Case- Socrates is a man
Deduction draws from a general rule, wherein the case and the result do not add anything new to what we know. For this reason, it is a type of restrictive and analytical reasoning that forces us to think in a constrained manner.

Induction draws from the observation of specific cases to then extract a general rule from them. It is a type of expansive and synthetic reasoning.

Abduction is based on conjecture and hypothesis. Basing itself on a general rule (unlike deduction, it is defined by a noticeable inadequacy), its conclusion lies in a highly uncertain case.

Table 7. Methods of human-scientific reasoning.

This happens because procedural games have excluded every definition of the word "game" that relates to leisure, since they must move in a deductive frame. It is important to remember that the greatness of the medium lies in its abductive power (Navarrete-Cardero et al. 2014). As critic Stanley Fish states, no theory (rule or norm) in post-modern society can change our personal beliefs (Norris 1998, 108). This fact greatly hampers the purported rhetoric effectiveness of these games (Table 7). In our perspective, procedural games could never serve as a means for the utopia, due to their deductive frame preventing the establishment of a rule, i.e. an ideology, from which all other plausible premises emanate in a restrictive and analytical manner. In these games, there is no room for conjecture and hypotheses, i.e. fundamental drivers of change and transformation of any given reality into a distinct one. Without abduction, there can be no change; without change, there can be no utopia.

It is paradoxical that a genre like that of walking simulators, whose origins were fraught with infamy, could have a specific and special seed of utopia. On the other hand, it is disheartening that the nature of this possibility of change can only be conceived in internal and personal terms, in a very individual manner. Certainly, as we have ascertained, the reluctance of the neoliberal society of today to accept any modifications or alternatives (Jameson 2005; Fisher 2009) has eliminated the utopic action in our lives. A single look out of the window is enough to prove that this statement is certain and substantial. As we have seen, the systemic criticism of the contradictions in the processes of our society is useless since the power to change them has been taken away from us by the new, inflexible and immutable order of the present neoliberalism. A videogame - in the case of those based on procedural rhetoric - attempting to demonstrate the contradictions of certain processes of our reality just to show them becomes the most accurate representation of the new human condition, as it lacks the ability to eliminate said contradictions. Everybody seems to have abandoned their dream of changing systemic processes that they bear no influence on. People fall into conformism and are forced to look inside themselves, urged to consider the search for a certain stability to be their only purpose in life. Without any possibility of creating a new, better order, a forceful interiorisation of the utopia is produced and this is eventually identified with the sole wish to create a personal, favourable world in an unfavourable context. In our opinion, walking simulators are the correlate of this existential phenomenon and its videoludic expression.

In conclusion, it is important to ratify one of the fundamental ideas of this research: the current inability of the videoludic medium to alter the environing reality underlines the separation, in modern societies, of the spheres - cultural, economic, political - advocated by Marcuse (1968) or, more recently, by Dean (2005) through 
his concept of "communicative capitalism". This problem is not exclusive to the videoludic medium: cinema and novels are, to this date, also unable to do so. The difference, as interpreted from the statements by Bogost (2017), lies in the unconscious existence of a global drive to distance videogames from any utopian attempt, i.e. its narrative aspect - the data suggests that this goal can only be pursued via narration - to reaffirm it in its nature as an entertainment device and artefact. In our view, the unique situation of videogames is not coincidental, but rather a condition induced by systemic determinations that can be considered a triumph of neoliberalism.

\section{References}

Aarseth, Espen. 1997. Cybertext: Perspectives on Ergodic Literature. Baltimore: JHU Press. Anthropy, Anna. 2012. Rise of the Videogame Zinesters: How Freaks, Normals, Amateurs, Artists, Dreamers, Drop-outs, Queers, Housewives, and People Like You are Taking Back an Art Form. New York: Seven Stories Press.

Balasopoulos, Antonis. 2008. Utopiae Insulae Figura: Utopian Insularity and the Politics of Form. Transtext(es) Transcultures, Journal of Global Cultural Studies. doi:10.4000/transtexts. 213

Bauman, Zygmunt. 2006a. Liquid Modernity. Cambridge: Polity Press.

Bauman, Zygmunt. 2006b. Living in Utopia. In Soundings 33: 1-13.

Bell, Daniel. 1996. The Cultural Contradictions of Capitalism. New York: Basic Books.

Benjamin, Walter. 1972. Iluminaciones II. Baudelaire. Un poeta en el esplendor del capitalismo. Madrid: Taurus.

Bogost, lan. 2007. Persuasive Games: The Expressive Power of Videogames. Massachusetts: MIT Press.

Bogost, Ian. 2017. Video Games Are Better Without Stories. Film, television, and literature all tell them better. So why are games still obsessed with narrative? The Atlantic. Accessed May 13, 2018. https://www.theatlantic.com/technology/archive/2017/04/video-gamesstories/524148/

Boltanski, Luc and Eve Chiapello. 2002. The New Spirit of Capitalism. London: Verso.

Bulut, Ergin. 2015. Playboring in the tester pit: The convergence of precarity and the degradation of fun in video game testing. Television \& New Media 16 (3): 240-258.

Bulut, Ergin, Robert Mejia and Cameron McCarthy. 2014. Governance through Philitainment: Playing the Benevolent Subject. Communication and Critical/Cultural Studies 11 (4): $342-$ 361.

Clark, Nicole. 2017. A Brief History of the "Walking Simulator", Gaming's Most Detested Genre. Salon. Accessed May 13, 2018. https://www.salon.com/2017/11/11/a-brief-history-ofthe-walking-simulator-gamings-most-detested-genre/

Costikyan, Greg. 2013. Uncertainty in Games. Cambridge: MIT Press.

Dean, Jodi. 2005. Communicative Capitalism: Circulation and the Foreclosure of Politics. Cultural Politics 1 (1): 51-74.

De Koven, Barnard. 2013. The Well-Played Game. A Player's Philosophy. Cambridge: MIT Press.

Deleuze, Gilles. 1968. Différence et répétition. Paris: Presses Universitaires de France.

Deleuze, Gilles and Félix Guattari. 1972. Anti-Oedipus: Capitalisme et schizophrénie. Paris: Les Editions de Minuit.

Dyer-Witheford, Nick and Greig de Peuter. 2010. Games of Multitude. The Fibreculture Journal 16.

Dyer-Witheford, Nick and Greig de Peuter. 2012. Imperio@play: videojuegos y capitalismo global. In Extra Life: 10 videojuegos que han revolucionado la cultura contemporánea, edited by Errata Naturae, 237-268. Madrid: Errata Naturae.

Eagleton, Terry. 2003. After Theory. New York: Basic Books. 
Eco, Umberto. 1979. Lector in fabula. La cooperazione interpretative nei testi narrative. Milan: Bompiani.

Finkielkraut, Alain. 1996. The Defeat of the Mind. New York: Columbia University Press.

Fisher, Mark. 2009. Capitalist Realism: Is There No Alternative? Hampshire: John Hunt Publishing.

Flanagan, Mary. 2003. Domestic. Maryflanagan.com. Accessed May 13, 2018. http://maryflanagan.com/work/domestic/

Foucault, Michel. 1969. Qu'est-ce qu'un auteur? Bulletin de la Société Française de Philosophie 63 (3): 73-104.

Frasca, Gonzalo. 2003. September 12th: A Toy World [online videogame]. Uruguay: Newsgaming.

Galloway, Alexander R. 2006. Gaming: Essays on Algorithmic Culture. Minneapolis: University of Minnesota Press.

Genette, Gerard. 1997. Palimpsests: Literature in the Second Degree. Nebraska: University of Nebraska Press.

Gray, John. 2005. False Dawn: The Delusions of Global Capitalism. London: Granta Books.

Hauser, Arnold. 1969. The Social History of Art. Vol. 3. London: Routledge.

Hermund, Frederik, Ole Fabricius Toubro, Jakob Elias Nielsen, Roman Spycher and Cristian

Selman. 2008. $3^{\text {rd }}$ World Farmer [online videogame]. 3rdWorldFarmer Team. San Francisco:

Arcade Town

Hicks, William. 2016. Why Walking Simulator Video Games Have Become So Political. Heatstreet. Accessed November 25, 2017. http://fsetyt.com/why-walking-simulator-videogames-have-become-so-political.html

Jameson, Fredric. 2005. Archaeologies of the Future: The Desire Called Utopia and Other Science Fictions. London: Verso.

Jenkins, Henry, Brett Camper and Alex Chisholm. 2009. From Serious Games to Serious Gaming. In Serious Games. Mechanics and Effects, edited by Ute Ritterfeld, Michael Cody and Peter Vorderer, 448-468. New York: Routledge.

Juul, Jesper. 2013. The Art of Failure: An Essay on the Pain of Playing Video Games. Cambridge: MIT Press.

Kücklich, Julian. 2005. Precarious Playbour: Modders and the Digital Games Industry. The Fibreculture Journal 5 (1). Accessed May 13, 2018. http://five.fibreculturejournal.org/fcj025-precarious-playbour-modders-and-the-digital-games-industry/

Lund, Arwid. 2014. Playing, Gaming, Working and Labouring: Framing the Concepts and Relations. tripleC: Communication, Capitalism \& Critique. Open Access Journal for a Global Sustainable Information Society 12 (2): 735-801.

Marcuse, Herbert. 1968. The Affirmative Character of Culture. In Negations: Essays in Critical Theory. London: The Penguin Press.

McGonigal, Jane. 2011. Reality Is Broken: Why Games Make Us Better and How They Can Change the World. New York: The Penguin Press.

Monticelli, Lara. 2018. Embodying Alternatives to Capitalism in the 21st Century. tripleC: Communication, Capitalism \& Critique 16 (2): 501-517.

Muriel, Daniel. 2017. Caminando en los límites del videojuego: un paseo por los walking simulators. Mondo Pixel. Accessed May 13, 2018. https://www.caninomag.es/caminandolos-limites-del-videojuego-paseo-los-walking-simulators/

Murray, Janet H. 1999. Hamlet on the Holodeck: The Future of Narrative in Cyberspace. Cambridge: MIT Press.

Navarrete-Cardero, José Luis, José Patricio Pérez-Rufí and Francisco Javier Gómez-Pérez. 2014. El pensamiento abductivo como fundamento ontológico de los videojuegos. Icono14 12 (2): 416-440.

Ninja Theory. 2017. Hellblade: Senua's Sacrifice. Cambridge: Ninja Theory Ltd.

Norris, Christopher. 1998. ¿Qué le ocurre a la postmodernidad? Tecnos. Madrid. 
Ortega, José. 2017. Los mejores Walking Simulators. IGN. Accessed May 13, 2018. http://es.ign.com/reportaje/118071/feature/los-mejores-walking-simulators

Racault, Jean-Michel. 1991. L'Utopie narrative en France et en Angleterre 1675-1761. Oxford: The Voltaire Foundation.

Schell, Jesse. 2014. The Art of Game Design: A Book of Lenses. Florida: CRC Press.

Singal, Jesse. 2016. Why the Video-Game Culture Wars Won't Die. NYMag. Accessed November 25, 2017. http://nymag.com/selectall/2016/09/why-the-video-game-culture-warswont-die-two-years-later.html

Touraine, Alain. 2001. Beyond Neoliberalism. Cambridge: Polity Press.

Turkle, Sherry. 1997. Seeing Through Computers. The American Prospect, 8 (31): 76-82.

Urban Dictionary. 2017. Social Justice Warrior. Accessed November 25, 2017. https://www.urbandictionary.com/define.php?term=social\%20justice\%20warrior

Vargas-Iglesias, Juan J. 2018. Making Sense of Genre: The Logic of Video Game Genre Organization. Games and Culture. OnlineFirst: 1-21.

Wark, McKenzie. 2006. Gamer Theory. Cambridge: Harvard University Press.

\section{About the Authors}

\section{Luis Navarrete-Cardero}

Luis Navarrete-Cardero has a PhD from the University of Seville, Spain. He is Coordinator of the Master in Videogames of the University of Seville and director of the collection on videogames of the publishing company Síntesis. He is also the author of numerous articles and books related to game studies. His latest publication is the book titled Spain Ludica. The Romantic Image of Spain Through Videogames (UOC, 2017). He is currently professor and coordinator of the subjects Hybrid Narrative Formats in the Digital Age, New Technologies of the Audiovisual Media and Videogame Script, belonging to the Department of Audiovisual Communication of the Faculty of Communication of the University of Seville.

Juan J. Vargas-Iglesias

Juan J. Vargas-Iglesias has a PhD from the University of Seville, Spain. He is a professor in the Audiovisual Communication and Advertising Department of the University of Seville, where he teaches subjects about postmodern fiction, digital culture and media criticism. He is the author and editor of some books related to media studies. His research articles have been published in peer-reviewed journals like Games and Culture and Semiotica: Journal of the International Association for Semiotic Studies. His current research focuses on the semiotics of genre in videogames. 